\title{
Cerebral blood flow and temporal lobe epileptogenicity
}

\section{Martin E. Weinand, M.D., L. Philip Carter, M.D., Waleed F. El-Saadany, M.D., Panayiotis J. Sioutos, M.D., David M. Labiner, M.D., and Kalarickal J. Oommen, M.D.}

Division of Neurosurgery, Department of Surgery and Department of Neurology, University of Arizona College of Medicine, Tucson, Arizona; and Departments of Neurosurgery and Neurology, University of Oklahoma College of Medicine, Oklahoma City, Oklahoma

Long-term surface cerebral blood flow $(\mathrm{CBF})$ monitoring was performed to test the hypothesis that temporal lobe epileptogenicity is a function of epileptic cortical perfusion. Forty-three bitemporal 2-hour periictal CBF studies were performed in 13 patients. Homotopic regions of temporal cortex maintained interictal epileptic cortical hypoperfusion and nonepileptic normal cortical CBF. At 10 minutes preictus, a statistically significant, sustained increase in $\mathrm{CBF}$ was detected on the epileptic temporal lobe. Two minutes preictus, there was approximation of $\mathrm{CBF}$ in the epileptic and nonepileptic temporal lobes. Thereafter, electrocorticographic (ECoG) and clinical seizure onset occurred. The linear relationship between $\mathrm{CBF}$ in the two hemispheres (epileptic and nonepileptic) was the inverse of normal $(\mathrm{y}=-0.347 \mathrm{x}$ $+62.767, \mathrm{r}=0.470, \mathrm{df}=95, \mathrm{p}<0.05)$. The data indicated a direct linear correlation between epileptic cortical CBF and seizure interval (frequency-1), a clinical measure of epileptogenicity $(\mathrm{r}=0.610, \mathrm{df}=$ $49, \mathrm{p}<0.05)$. Epileptogenicity was also found to be a logarithmic function of the difference between nonepileptic and epileptic cortical perfusion $(\mathrm{r}=0.564$, $\mathrm{df}=58, \mathrm{t}=5.20, \mathrm{p}<0.05)$. The results showed that progressive hypoperfusion of the epileptic focus correlated with a decreased seizure interval (increased epileptogenicity). Increased perfusion of the epileptic focus correlated with an increased seizure interval (decreased epileptogenicity). The fact that CBF alterations precede ECoG seizure activity suggests that vasomotor changes may produce electrical and clinical seizure onset.

Key Words * cerebral blood flow * epilepsy * epilepsy surgery * epileptogenicity * subdural electrode * temporal lobe seizure

The ultimate goal of temporal lobe epilepsy surgery is to render the patient seizure free.[50] Success depends substantially on the validity of data used for seizure focus localization.[49] Methods available to localize the epileptic focus include clinical seizure phenomenology; neurological examination; neuropsychological testing; magnetic resonance imaging; functional brain imaging with single-photon emission computerized tomography (SPECT) and positron emission tomography (PET); video/scalp electroencephalographic (EEG) monitoring; intraoperative electrocorticography; and video electrocorticographic (ECoG) monitoring with depth, subdural, or epidural electrodes.

Recently, there has been a trend in epilepsy centers that perform invasive monitoring to do so less often.[16] Because invasive monitoring is decreasing in surgical candidates, [1,2,4-6,12-14,16, $23,26-28,31,36-39,43,44]$ there is need to improve our understanding of other pathophysiology that 
might be amenable to noninvasive detection.

Localization of the epileptic focus using cerebral blood flow (CBF) methods is supported by the observation that SPECT detects cerebral hypoperfusion concordant with interictal scalp EEG epileptic activity in $50 \%$ to $60 \%$ of patients. $[5,6,23,27,36,38,39,43,44]$ Early postictal hyperperfusion is concordant with ictal scalp EEG for focal seizure localization in approximately $70 \%$ of patients.[27,29,38]

This work involves the long-term study of bilateral temporal lobe thermal diffusion flowmetry (TDF) (Fig. 1). The safety and efficacy of TDF CBF monitoring has been extensively documented.[7-10,19,40,42,51] Thermal diffusion flowmetry applies a thermal gradient directly to the cerebral cortex using a heating element and neutral thermal sensor. Using the isocaloric principle, this technique provides a constant power source while varying the temperature between the heated and neutral plate. The temperature difference between the plates is correlated with CBF.[51] The sensor is designed to shut off at $42^{\circ} \mathrm{C}$ to prevent the cortex from overheating. There has been no evidence of compromised safety or efficacy related to heat dispersion from the heating element.

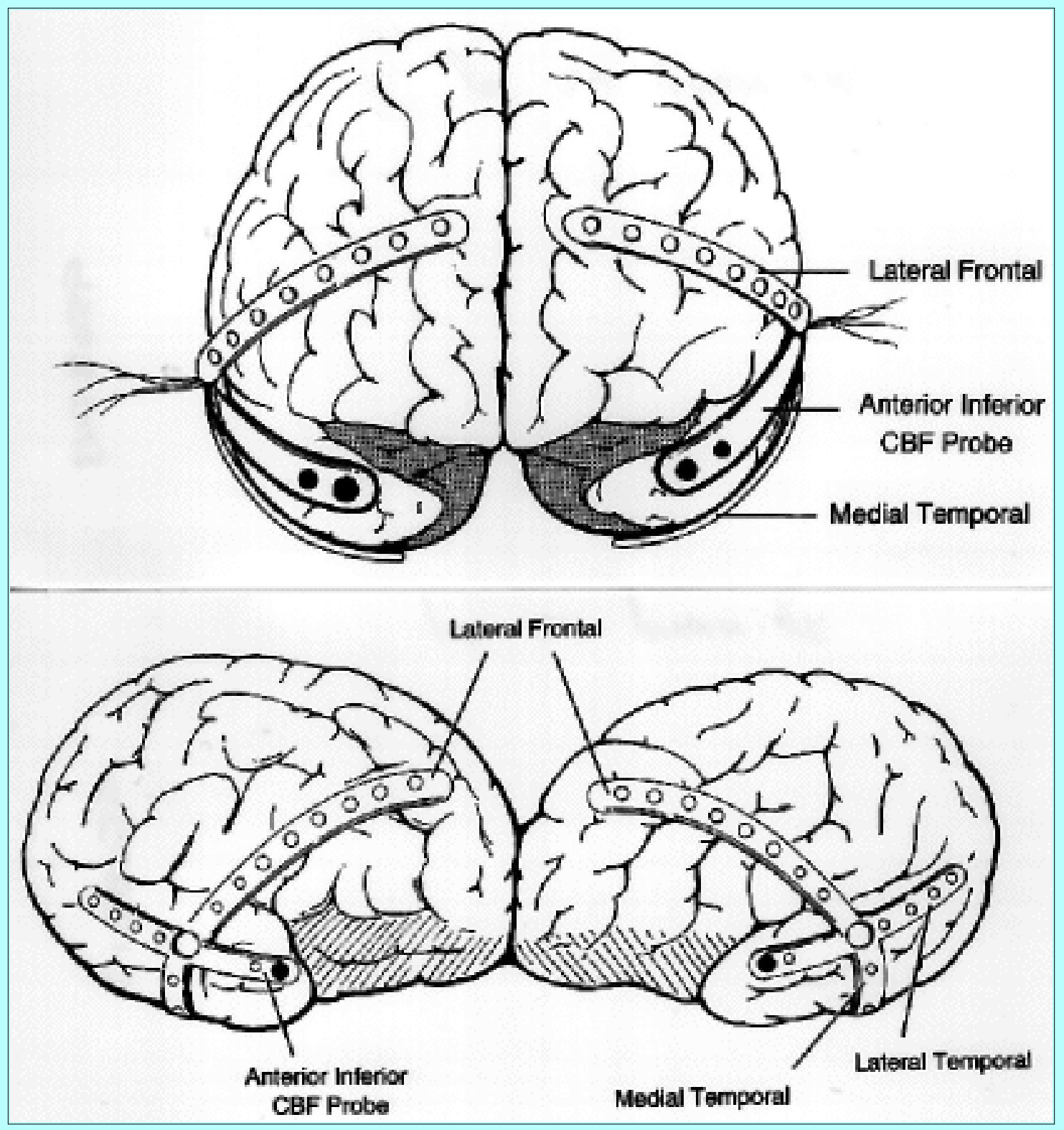

Fig. 1. Ilustrations depicting anterior (upper) and lateral (lower) views of standard subdural 
strip electrode montage for continuous electrocorticographic and cerebral blood flow (CBF) monitoring in temporal lobe epilepsy. The CBF sensor consists of a heated and neutral plate. The temperature difference between the two plates is correlated with $\mathrm{CBF}$.

Data derived from surface TDF correlate significantly with results obtained by other noninvasive methods such as hydrogen and isotope clearance and nitrous oxide CBF techniques.[7-10,19,51] This report analyzes TDF data to test the hypothesis that epileptogenicity is a function of epileptic cortical perfusion.

\section{CLINICAL MATERIAL AND METHODS}

\section{Patient Population}

We studied a selected series of 13 patients with medically intractable complex partial seizures. A magnetic resonance image of the brain was obtained in each patient to detect any structural lesions. All patients underwent video/scalp EEG monitoring, which proved to be insufficient to localize focal seizures due to at least one of the following reasons: 1) EEG onset was too diffuse to be localized to a single lobe of brain; 2) bilateral EEG onset; 3) EEG onset followed clinical seizure onset; or 4) EEG onset was obscured by electromyographic or other artifact. Therefore, each patient underwent implantation of bilateral subdural strip electrodes for long-term ECoG monitoring.[50,54] At the time of subdural strip placement, all patients also underwent implantation of bilateral subdural anteroinferior temporal surface cortical CBF thermal diffusion sensors (Flowtronics Corp., Phoenix, Arizona)[47] in accordance with the protocol approved by the University of Arizona Human Subjects Committee. Anticonvulsant medication was discontinued immediately prior to implantation of subdural strip electrodes.

\section{Data Acquisition}

Surface CBF was continuously measured in $\mathrm{ml} / 100 \mathrm{~g} /$ minute over bilateral anterolateral temporal lobes in a timed sequence with video/subdural ECoG and clinical phenomenology. Cerebral blood flow data were digitized and transferred to a database for analysis. Electrical seizure onset was defined as the first sustained change from background ECoG activity.[51]

\section{Cerebral Blood Flow Monitoring Periods}

All patients were continuously monitored. The mean duration in hours between seizures (that is, seizure interval or frequency-1) was noted. Bitemporal CBF during the 60-minute period preceding and following the ictus was measured. The interictal period was defined as 60 to 20 minutes before the ictus (-60 to -20$)$. The preictal period was defined as 20 to 1 minutes before the ictus $(-20$ to -1$)$.[50] We defined the early preictal period as the first statistically significant sustained change in CBF from interictal values.[50] In our protocol using SPECT and surface CBF data we defined the early postictal, postictal, and late postictal periods as 1 to 5,10 to 40, and 50 to 60 minutes, respectively, following clinical seizure onset (Fig. 2).[46,47] 


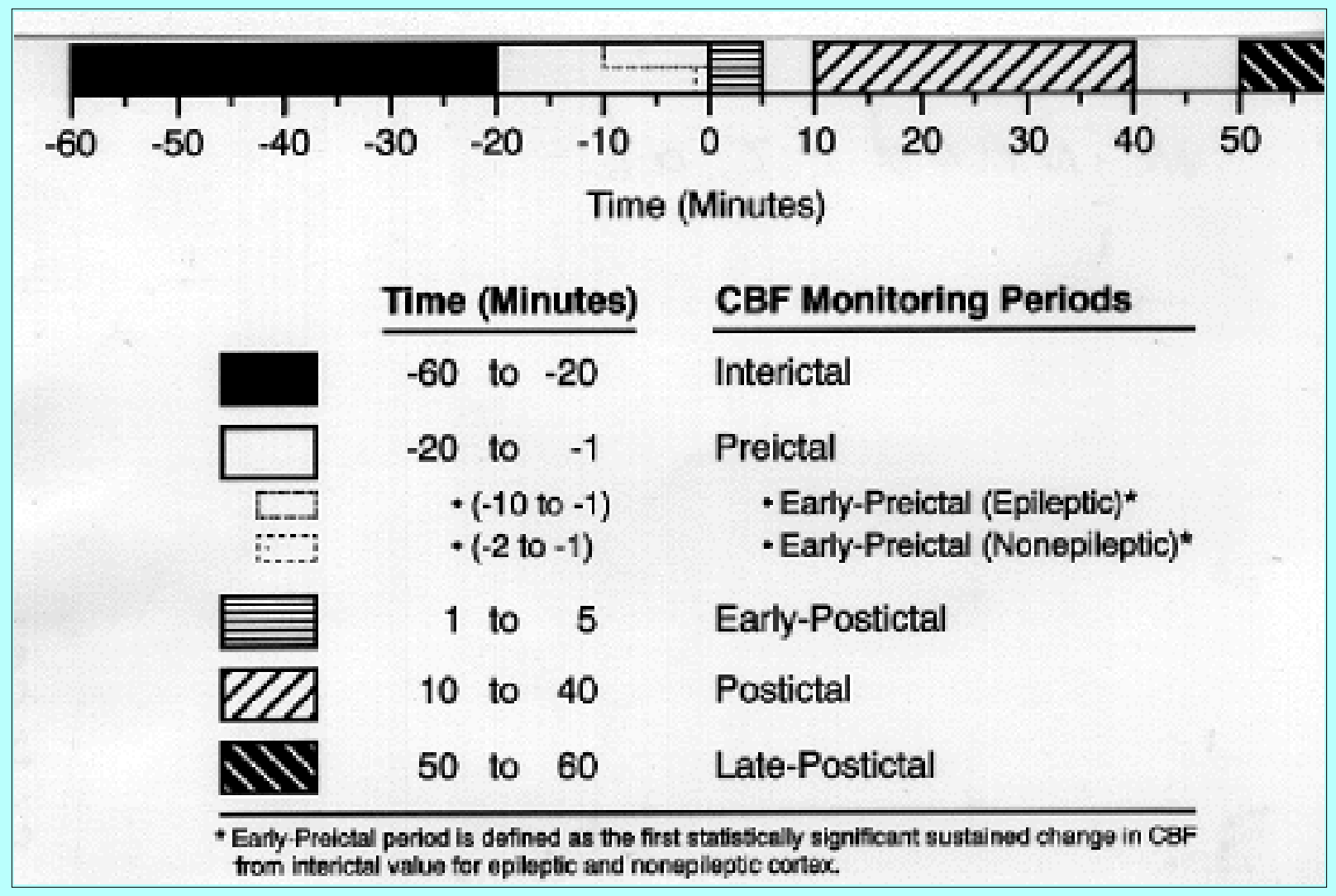

Fig. 2. Chart illustrating definitions of periictal cerebral blood flow (CBF) monitoring periods.

\section{Statistical Analysis}

All CBF data were analyzed to assess correlation between epileptic and nonepileptic temporal lobes and with seizure interval. Univariate statistical analysis was conducted on all data from the 43 periictal periods in all patients using the unpaired Student t-test. To evaluate reproducibility and reliability of the CBF data, multiple regression analysis of variance (ANOVA) was performed on the mean CBF data obtained in all patients during all periictal measurement periods. The results of the ANOVA were expressed as an F ratio. Statistical significance was defined as a probability value of less than 0.05 .

\section{RESULTS}

\section{Patient Population}

Forty-three 2-hour periictal periods in 13 patients were studied with bilateral subdural temporal cortical CBF sensors. There were six males and seven females with a mean age of 36 years (range 12-50 years). Ictal subdural strip ECoG monitoring localized the epileptic focus to medial temporal in eight patients, the lateral temporal lobe in four patients, and medial and lateral temporal lobe in one. 


\begin{tabular}{|c|c|}
\hline \multicolumn{2}{|c|}{$\begin{array}{l}\text { TABLE } 1 \\
\text { DEMOGRAPHIC AND CL NICAL DATA IN } 13 \text { PATIENTS STUDIED WITH LONG-TERM } \\
\text { SURFACE CORTICAL CEREBRAL BLOOD FLOW MON TORING }\end{array}$} \\
\hline \multicolumn{2}{|l|}{ Characteristic } \\
\hline $\begin{array}{l}\text { gender } \\
\text { age (urs) } \\
\text { ictal subdural } \\
\text { EOOG focus }\end{array}$ & $\begin{array}{l}7 \text { females } \\
6 \text { males } \\
\text { mean } 36 \\
\text { range } 12-50 \\
\text { medial tem poral : } 8 \text { patients } \\
\text { lateral tem poral: } 4 \text { patients } \\
\text { regional (medial \& lateral) tem poral: } 1 \text { patient } \\
\text { mean }-0.08 \pm 0.03 \\
\text { range }-0.31 \text { to } 0.08 \\
\text { medial tem poral sclerosis: } 4 \text { patients } \\
\text { hippocam pal atrophy: } 4 \text { patients } \\
\text { tem poral horn dilation: } 2 \text { patients } \\
\text { insular cortex cyst: } 1 \text { patient } \\
\text { parahippocampal gyrus caiernous hem an- } \\
\text { gioma: } 1 \text { patient } \\
\text { tem poral lobe migrational disonder: } 1 \text { patient } \\
\text { mean } 18.30 \pm 1.21\end{array}$ \\
\hline \multicolumn{2}{|c|}{$\begin{array}{l}\text { ₹Abtreviations: } E C O G \text { electrocorticographic; MR = magne tic resonance; } \\
\text { sE = standard error of the mean. } \\
\dagger \text { The } E C O G \text { onset relative to clinical seizure onset at time } 0 \text { minutes, nega- } \\
\text { ti ie and positive values indicate time before and after dinical seizure onset, } \\
\text { respectively. }\end{array}$} \\
\hline
\end{tabular}

During long-term monitoring, the mean duration between seizures (seizure interval, frequency-1) was $18.3 \pm 1.21$ hours. Magnetic resonance imaging of the brain detected epileptic temporal lobe structural abnormality as follows: medial temporal sclerosis four patients, hippocampal atrophy four patients, temporal horn dilation two patients, insular cortical cyst one patient, parahippocampal gyrus cavernous hemangioma one patient, and temporal lobe migration disorder one patient (Table 1).

\begin{tabular}{|c|c|c|c|}
\hline \multicolumn{4}{|c|}{$\begin{array}{c}\text { TABLE } 2 \\
\text { TEMPORAL LOBE CEREBRAL BLOOD FLOW MONTORING DATA }\end{array}$} \\
\hline $\begin{array}{l}\text { Mean CBF } \\
\text { val ue† }\end{array}$ & $\begin{array}{l}\text { Epil eptic } \\
\text { Temporal Lobe }\end{array}$ & $\begin{array}{l}\text { Nonepileptic } \\
\text { Temporal Lobe }\end{array}$ & $\begin{array}{l}\text { Significance } \\
\text { (p Val we) }\end{array}$ \\
\hline $\begin{array}{l}\text { in terictal } \\
\text { early preictal } \\
\text { early postictal } \\
\text { postictal } \\
\text { late postictal } \\
\text { change from interictal to } \\
\text { early preictal }\end{array}$ & $\begin{array}{l}39.3 \pm 1.8 \\
46.3 \pm 1.1 \\
47.2 \pm 3.9 \\
42.1 \pm 2.8 \\
31.3 \pm 3.3 \\
+7.0 \pm 3.1\end{array}$ & $\begin{array}{l}55.4 \pm 3.4 \\
51.4 \pm 3.8 \\
65.3 \pm 3.3 \\
57.4 \pm 2.8 \\
68.4 \pm 9.3 \\
-4.0 \pm 2.5\end{array}$ & $\begin{array}{l}0.000 \\
0.088 \\
0.001 \\
0.001 \\
0.002 \\
0.031\end{array}$ \\
\hline \multicolumn{4}{|c|}{$\begin{array}{l}\text { "Data are presented as the mean } \pm \text { the standard error of the mean. Abbre } \\
\text { viation: CBF = ceretral blood flow in ml/h00 gininute. } \\
\dagger \text { The CBF monitoring periods are defined in Fig. } 2 \text {. }\end{array}$} \\
\hline
\end{tabular}

\section{Univariate Statistical Analysis}

Cerebral blood flow data are summarized for all patients in Table 2 and Figs. 3 to 7. In interictal, preictal, and early and late postictal periods, there was an inverse linear relationship between epileptic and nonepileptic temporal lobe CBF $(\mathrm{r}=0.749, \mathrm{df}=34, \mathrm{p}<0.05 ; \mathrm{r}=0.487$, $\mathrm{df}=22, \mathrm{p}<0.05 ; \mathrm{r}=0.509$, $\mathrm{df}=$ $14, \mathrm{p}<0.05$; and $\mathrm{r}=0.548, \mathrm{df}=22, \mathrm{p}<0.05$; respectively). Bitemporal CBF correlation data for these 
periictal periods are summarized in Fig. $5(\mathrm{r}=0.470, \mathrm{df}=95, \mathrm{p}<0.05)$. In the interictal period, epileptic cortex was hypoperfused relative to nonepileptic cortex $(39.3 \pm 1.8$ vs $55.4 \pm 3.4 \mathrm{ml} / 100 \mathrm{~g} / \mathrm{minute}, \mathrm{p}<$ 0.05 ) (Table 2). At 20 minutes preictus, $\mathrm{CBF}$ began to increase in the epileptic temporal lobe, reaching statistical significance, relative to interictal baseline, at 10 minutes preictus $(39.3 \pm 1.8$ to $46.3 \pm 1.1$ ml/100 g/minute, $\mathrm{p}<0.05$ ) (Table 2 and Fig. 3).

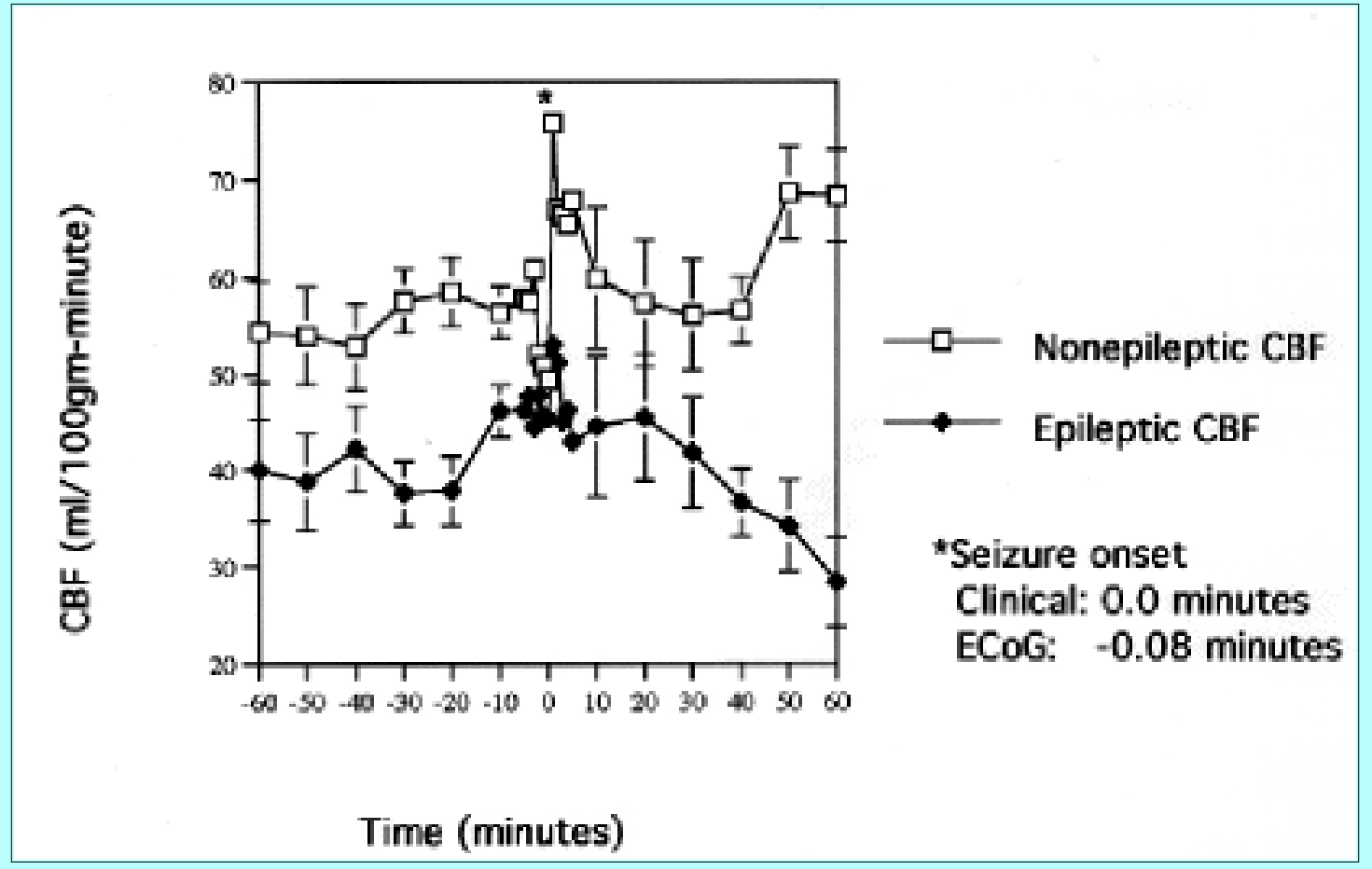

Fig. 3. Graph depicting the mean long-term continuous bitemporal cerebral blood flow (CBF) monitoring data from epileptic and nonepileptic temporal cortex. The CBF data are given in $\mathrm{ml} / 100 \mathrm{~g} / \mathrm{minute}$; clinical seizure onset at 0 minutes, negative and positive time values precede and follow clinical seizure onset, respectively. The y-axis bars illustrate the standard error of the mean. ECoG = electrocorticograph.

During the transition from interictal to early preictal periods, epileptic temporal lobe CBF increase and nonepileptic temporal lobe $\mathrm{CBF}$ decrease were statistically significant relative to interictal values $(7 \pm$ $3.1 \mathrm{vs}-4.0 \pm 2.5 \mathrm{ml} / 100 \mathrm{~g} /$ minute, $\mathrm{p}<0.05$ ) (Table 2). At 2 minutes preictus, the inverse linear correlation between epileptic and nonepileptic cortical CBF disappeared $(r=0.108, \mathrm{df}=14, \mathrm{p}>0.05)$ and epileptic and nonepileptic cortical CBF became approximately the same $(46.3 \pm 1.1$ and $51.4 \pm 3.8$ $\mathrm{ml} / 100 \mathrm{~g} /$ minute, respectively, $\mathrm{p}>0.05$ ) (Table 2). Thereafter, ECoG and clinical seizure onset occurred, followed by CBF increase in both temporal lobes (Figs. 3 and 4). 


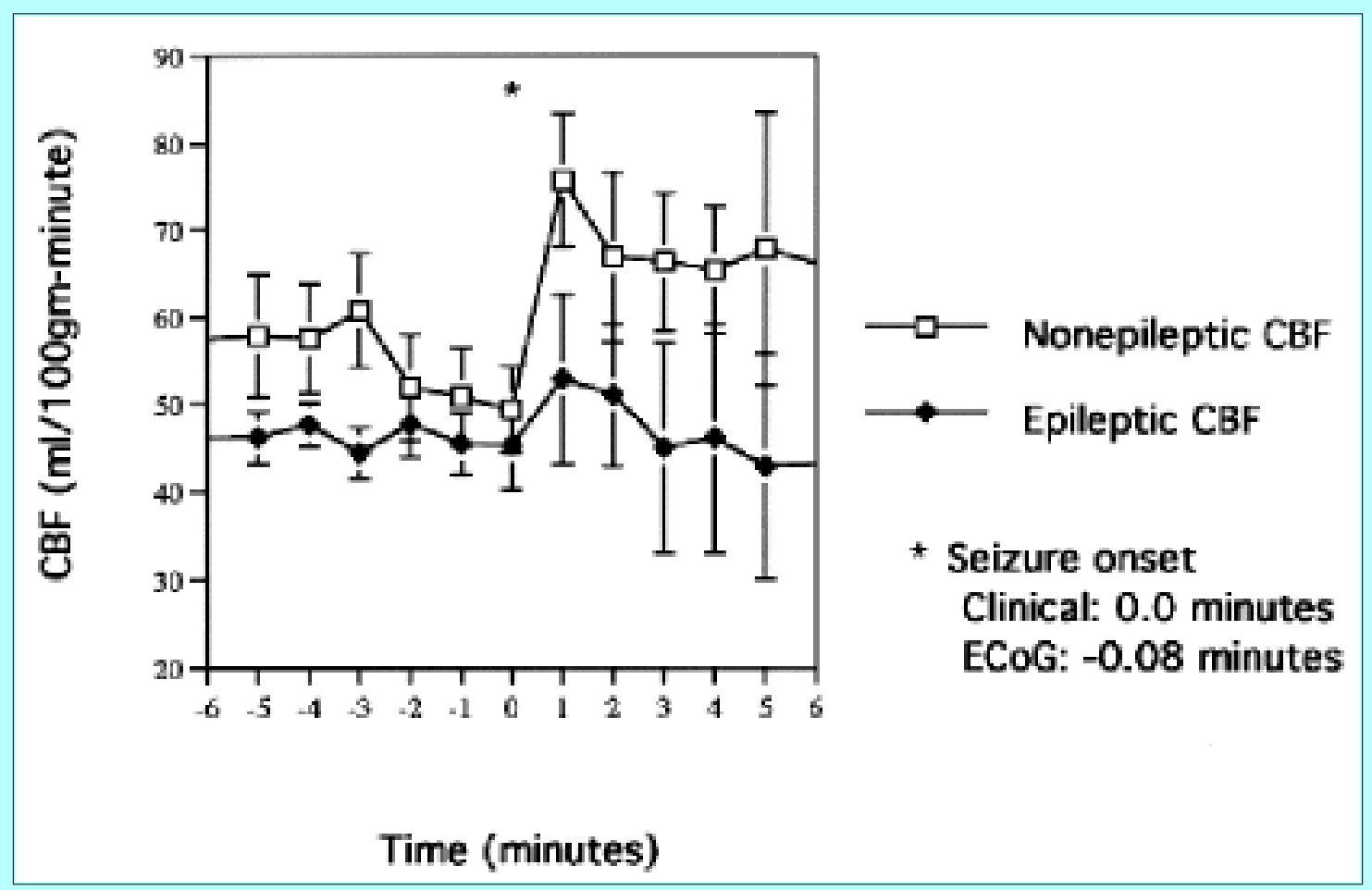

Fig. 4. Graph displaying the mean data from continuous surface cerebral blood flow (CBF) monitoring in the epileptic and nonepileptic temporal lobe. The y-axis bars illustrate the standard error of the mean. At 2 minutes preictus, statistical approximation of epileptic and nonepileptic CBF occurs. Thereafter, electrocorticographic (ECoG) seizure onset is recorded, followed by clinical seizure phenomenology.

At 2 minutes postictus, the inverse relationship between epileptic and nonepileptic CBF resumed ( $\mathrm{r}=$ $0.509, \mathrm{df}=14, \mathrm{p}<0.05)$. Early postictal, postictal, and late postictal epileptic temporal lobe CBF was significantly decreased compared to nonepileptic temporal lobe ( $47.2 \pm 3.9$ vs $65.3 \pm 3.3 ; 42.1 \pm 2.8$ vs $57.4 \pm 2.8$; and $31.3 \pm 3.3$ vs $68.4 \pm 9.3 \mathrm{ml} / 100 \mathrm{~g} /$ minute, respectively, $\mathrm{p}<0.05$ ) (Table 2 ). 


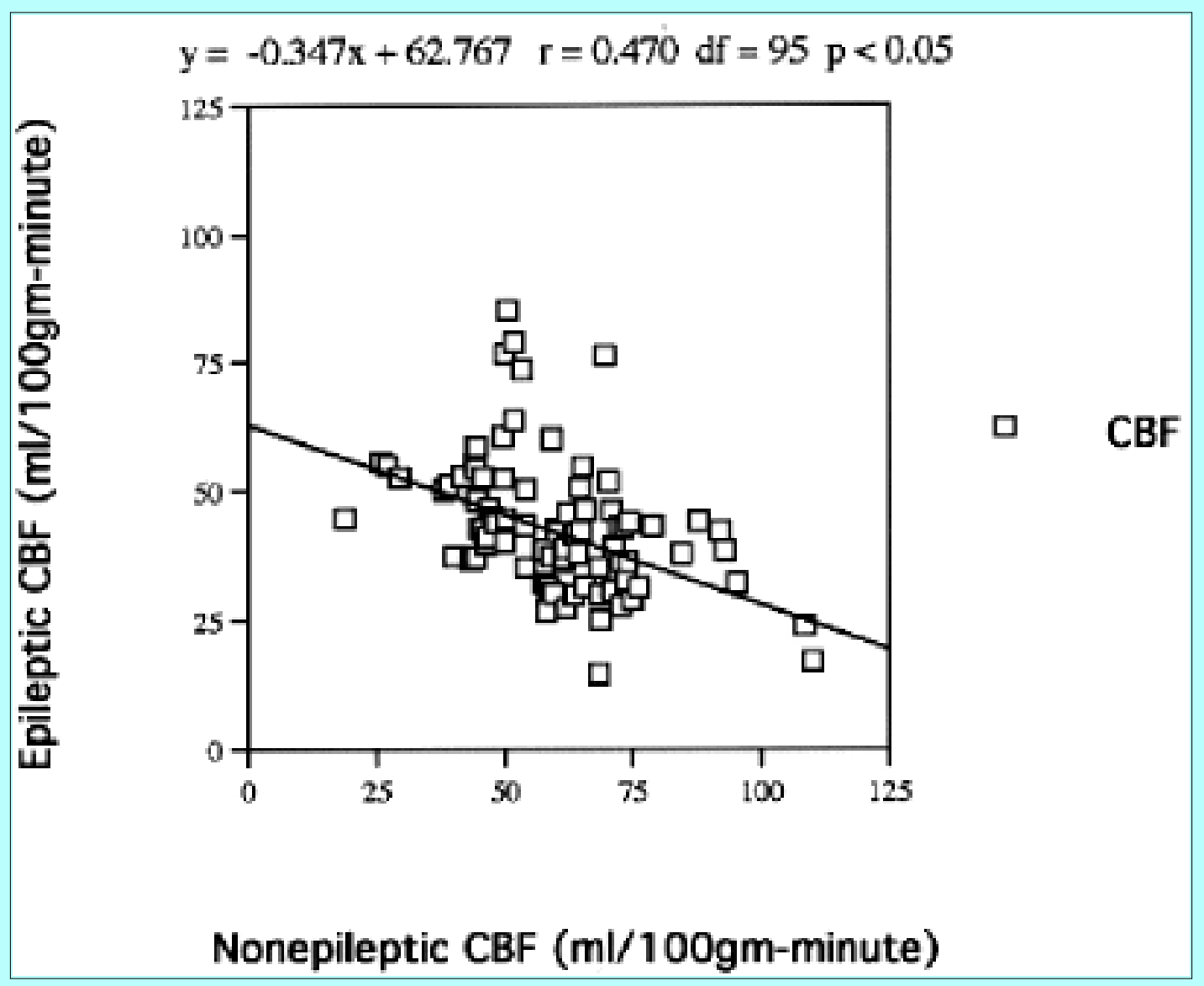

Fig. 5. Graph showing the statistically significant linear correlation between epileptic and nonepileptic temporal lobe cerebral blood flow (CBF) during the 2-hour periictal period. Note the negative slope of the $\mathrm{CBF}$ relationship between the two hemispheres. In contrast, for normal brain, the CBF correlation between the two hemispheres has been shown to be linear, but with a positive slope.

In interictal, early preictal, and early and late postictal periods, increasing epileptic temporal lobe CBF was significantly correlated in a direct linear fashion with increasing seizure interval (that is, decreasing epileptogenicity) $(\mathrm{r}=0.610, \mathrm{df}=49, \mathrm{p}<0.05)$. Conversely, the lower the epileptic $\mathrm{CBF}$, the greater the epileptogenicity (Fig. 6). 


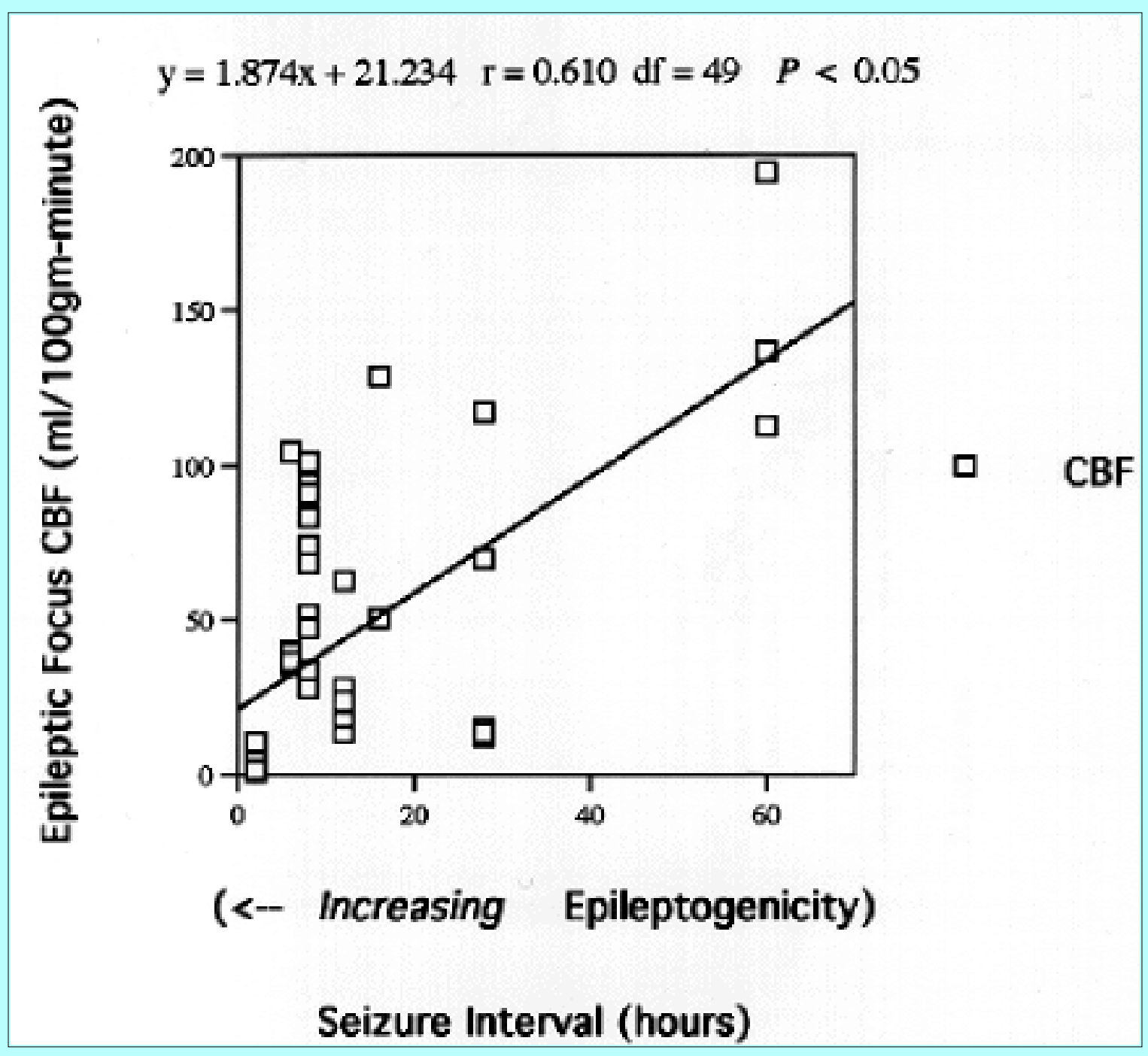

Fig. 6. Graph illustrating the linear relationship between epileptic temporal lobe cerebral blood flow (CBF) and seizure interval (frequency-1). At all times, with the exception of 2 minutes immediately before and after the ictus, seizure focus CBF monitoring is correlated with seizure interval. Seizure interval increases and epileptogenicity decreases from left to right. Increasing epileptogenicity is a function of progressive seizure focus hypoperfusion.

During the 2-hour periictal period, no statistically significant relationship was detected between nonepileptic temporal lobe CBF and seizure interval $(r=0.074, \mathrm{df}=48, \mathrm{p}>0.05)$. However, there was a significant logarithmic correlation between the difference in nonepileptic and epileptic cortical CBF and seizure interval $(\mathrm{r}=0.564, \mathrm{df}=58, \mathrm{t}=5.2, \mathrm{p}<0.05)$. As epileptic cortical CBF increased to approximate and exceed nonepileptic $\mathrm{CBF}$, the seizure interval progressively increased (epileptogenicity decreased) (Fig. 7). 


\section{$y=-98.536 \operatorname{LOG}(x)+98.932 \quad r=0.564 d f=58 \quad t=5.20 p<0.05$}

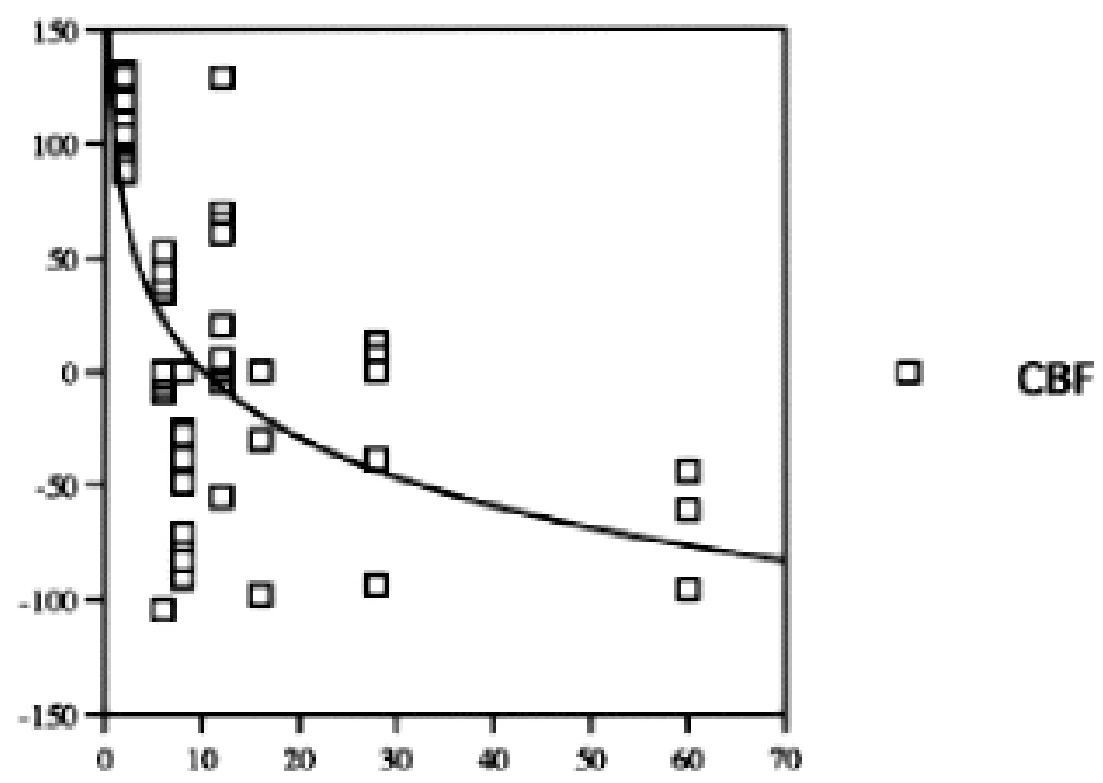

(<-- Increasing Epileptogenicity)

Seizure Interval (hours)

Fig. 7. Graph showing that at all times, with the exception of 2 minutes immediately before and after the ictus, there is a statistically significant logarithmic correlation between the difference in nonepileptic and epileptic cortical cerebral blood flow (CBF) and seizure interval (frequency-1). As CBF in the epileptic lobe approaches and exceeds that of the nonepileptic temporal lobe, there is a progressive increase in seizure interval (that is, a decrease in epileptogenicity).

\section{Multiple Regression ANOVA}

Multiple regression ANOVA of data obtained in all patients detected no statistically significant differences in mean CBF data, within epileptic and nonepileptic categories, respectively, during interictal $(\mathrm{F}=0.181, \mathrm{p}>0.05$ and $\mathrm{F}=0.226, \mathrm{p}>0.05$; respectively); early preictal $(\mathrm{F}=0.000, \mathrm{p}>0.05$ and $\mathrm{F}=$ $0.017, \mathrm{p}>0.05$; respectively); early postictal $(\mathrm{F}=0.225, \mathrm{p}>0.05$ and $\mathrm{F}=0.805, \mathrm{p}>0.05$; respectively); postictal $(\mathrm{F}=1.213, \mathrm{p}>0.05$ and $\mathrm{F}=0.181, \mathrm{p}>0.05$; respectively); and late-postictal $(\mathrm{F}=0.757, \mathrm{p}>$ 0.05 and $F=0.000, p>0.05$; respectively) periods. These results confirm that, within epileptic and nonepileptic categories during all periictal periods for all patients, there was no significant variation in CBF.

\section{DISCUSSION}

There has been considerable study of CBF patterns in humans without epilepsy.[3,11,30,52,56] In normal brain, there is significant correlation of $\mathrm{CBF}$ values between similar regions of the two hemispheres.[3] 
In patients with an ischemic region in one hemisphere, the most sensitive measure of CBF is obtained by comparison of the normal hemisphere to the identical region of contralateral diseased cortex.[17]

\section{Interictal Seizure Focus CBF Monitoring}

Penfield, et al.,[35] observed that epileptic lesions of all types showed cytological evidence of "progressive small ischemias." Interictal hypoperfusion of the epileptic focus has been confirmed with (133Xe)-SPECT,[25] HMPAO SPECT,[12] and (15O)H2O, (15O)O2, (15O)CO2, and (13N)NH3 PET.[1,18,28,32,40,55] During long-term subdural CBF monitoring, significant interictal epileptic focus hypoperfusion has been recorded.[47,48] Although cerebral hypoperfusion is the most common CBF manifestation of the interictal focus, false localization and lateralization occur with noninvasive interictal CBF imaging (for example, SPECT and PET) [5,6,13,23,27,36,38,39,43,44] and surface CBF recording[48] in $40 \%$ to $50 \%$ of patients. However, technical limitations of TDF restrict monitoring to the lateral temporal lobe. Insulation surrounding CBF contacts limits strip flexibility, precluding conformation to the irregular inferior temporal lobe surface.[47] Localization of temporal lobe epileptic foci using TDF might improve if future designs permit medial temporal lobe recording.

\section{Early Postictal CBF Monitoring}

Victor Horsley directly observed hyperperfusion of brain in a patient experiencing a seizure.[21] After intraoperative cortical stimulation, Penfield, et al.,[35] reported hyperperfusion associated with focal seizure activity. Gibbs and colleagues[20] detected ictal cerebral hyperperfusion using an internal jugular vein thermocouple. Measuring temperature with a hippocampal depth electrode, Dymond and Crandall[15] inferred qualitative postictal increases in epileptic cortical CBF preceding changes in nonepileptic cortex. Functional brain imaging has recorded postictal hyperperfsuion using (133Xe)-CBF,[22] (99mTc)HMPAO SPECT,[14,31] (123I) HIPDM SPECT,[23] and (15O)O2 PET.[18] During surface CBF monitoring, there is significant overlap between early postictal epileptic and nonepileptic temporal lobe CBF.[47] False-positive rates for early postictal epileptic focus localization with SPECT has been reported to be as high as 42\%.[49] False-positive and nonlocalization emphasizes the need for concordant localizing data when $\mathrm{CBF}$ techniques are used for early postictal seizure focus detection.[47,49]

\section{Late Postictal CBF Monitoring}

During the late postictal period, Penfield[33] and coworkers[35] observed epileptic cortical anemia associated with vasoconstriction and decreased CBF in brain distant from the focal seizures. The results of the current study are consistent with previous conclusions that late postictal lateral temporal cortical hypoperfusion is most pronounced on the side of ictal onset[37,38] and useful in focal seizure localization.[1,38,47,48]

\section{Epileptogenicity and Seizure Focus CBF Monitoring}

To test Penfield's[33,34] cerebrovascular hypotheses, seizure interval (frequency-1), a clinical measure of epileptogenicity,[48,53] was statistically analyzed. The data indicate a linear relationship between epileptic cortical CBF and seizure interval (Fig. 6). Increased perfusion of the epileptic focus is correlated with increased seizure interval (decreased epileptogenicity). Progressive hypoperfusion of the epileptic focus is correlated with decreased seizure interval (increased epileptogenicity). The results are consistent with Penfield's[34] hypothesis that epileptic seizures are a function of "progressive small ischemias." 
Progressive neuronal ischemia has been proposed as one theory of epileptogenesis for cortex exposed to chronic vascular steal.[33,34,45] Ongoing ischemia of the epileptic focus is associated with reduced oxygen metabolism and regional blood flow but increased seizure focus oxygen extraction fraction $(\mathrm{OEF}) .[2]$ Because OEF is normal with reduced CBF during normal autoregulation, increased OEF suggests the epileptic focus is ischemic.[34,45] The results of the current study support the conclusion that increasing epileptogenicity is a function of progressive epileptic cortical hypoperfusion.

\section{Epileptogenicity and Vasomotor Reactivity}

In normal circumstances, similar regions of both hemispheres are under uniform vasomotor control.[3,24] Vasodilatory stimuli produce bilateral CBF increases in homotopic vascular territories as a direct linear function of CBF in analogous regions of both hemispheres.[11] Penfield hypothesized that, "physiological instability of the blood vessels seems to be the abnormal state common to epileptics of all varieties"[33] and postulated that, "some undiscovered secret of cerebral circulation is the ultimate cause of epilepsy, I fancy."[34] The results of the current study suggest that vasomotor activity in the epileptic and nonepileptic temporal lobe is correlated; but the relationship is the inverse of normal (Fig. 5).

\section{Interictal to Ictal Transition}

Seizure onset has been defined as the first sustained electrophysiological change from background activity.[49,51] The extent to which electrophysiological change precedes clinical seizure onset has been considered one measure of the accuracy with which the seizure focus is localized.[49,50] Failure to localize the seizure focus with ictal EEG recording has been defined by EEG onset as occurring after clinical seizure onset.[49,51,53] However, whether ictal ECoG onset precedes or follows clinical seizure phenomenology has no prognostic value for seizure outcome following epileptic focus resection.[50]

The results of this study confirm previous reports that ictal ECoG onset is not the sentinal physiological event signaling impending clinical seizure.[41,47] Ictal ECoG seizure onset is a result of some prior fundamental pertubation. Electrocorticographic and clinical onset are preceded by significant alterations in $\mathrm{CBF}$ in both epileptic and nonepileptic cortex. Beginning approximately 20 minutes preictus, epileptic cortical CBF increases.[47,(and unpublished data)] At approximately 10 minutes preictus, epileptic cortical CBF increases significantly from ischemic levels. Approximately 2 minutes prior to ECoG onset, nonepileptic CBF is significantly decreased, approximating epileptic CBF (Figs. 3 and 4). Contralateral homotopic nonepileptic hypoperfusion is unique to the early preictal period, associated with loss of reciprocal epileptic and nonepileptic CBF correlation, and detected minutes before ECoG and clinical seizure onset.

As epileptic CBF approximated nonepileptic CBF, the seizure interval increased. Because of the logarithmic correlation between the difference in nonepileptic and epileptic CBF and seizure interval, it is possible that a small increase in epileptic cortical perfusion could substantially reduce epileptogenicity (Fig. 7). Early preictal epileptic cortical CBF increase may be a protective vasomotor response to some fundamental pertubation initiating the ictus. Seizure may result from failure of this protective vasomotor response to perfuse the seizure focus adequately and reduce epileptogenicity.

\section{CONCLUSIONS}

The results of this study suggest that epileptogenicity is a function of epileptic cortical perfusion. Electrical and clinical seizure onsets appear to be epiphenomena that are preceded by significant changes in $\mathrm{CBF}$. Whether early preictal CBF changes are due to redistribution from nonepileptic to epileptic 
cortex, changes in metabolic activity, or some other factor cannot be determined from the data. Further research is needed to discover the pertubation causing preictal alterations in epileptic and nonepileptic $\mathrm{CBF}$.

\section{ACKNOWLEDGMENT}

The authors thank Dr. Allan J. Hamilton for review of the manuscript.

\section{References}

1. Berkovic SF, Newton MR, Chiron C, et al: Single photon emission tomography, in Engel J Jr (ed): Surgical Treatment of the Epilepsies, ed 2. New York: Raven Press, 1993, pp 233-243

2. Bernardi S, Trimble M, Fracowiak RS, et al: An interictal study of partial epilepsy using positron emission tomography and the oxygen-15 inhalation technique. J Neurol Neurosurg Psychiatry 46:473-477, 1983

3. Blauenstein UW, Halsey JH Jr, Wilson EM, et al: 133-Xenon inhalation method. Analysis of reproducibility: some of its physiological implications. Stroke 8:92-102, 1977

4. Bonte FJ, Devous MD Sr, Stokely EM, et al: Single-photon computed tomographic determination of regional brain blood flow in the seizure disorders. Am J Physiol Imaging 3:30-31, 1988

5. Bonte FJ, Devous MD Sr, Stokely EM, et al: Single-photon tomographic determination of regional cerebral blood flow in epilepsy. AJNR 4:544-546, 1983

6. Bonte FJ, Stokely EM, Devous MD Sr, et al: Single-photon tomographic study of regional cerebral blood flow in epilepsy. Arch Neurol 40:267-270, 1983

7. Carter LP, Erspamer R, Bro WJ: Cortical blood flow: thermal diffusion vs isotope clerance. Stroke 12:513-518, 1981

8. Carter LP, Erspamer R, White WL, et al: Cortical blood flow during craniotomy for aneurysms. Surg Neurol 17:204-208, 1982

9. Carter LP, Raudzens PA, Gaines C, et al: Somatosensory evoked potentials and cortical blood flow during craniotomy for vascular disease. Neurosurgery 15:22-28, 1984

10. Carter LP, White WL, Atkinson JR: Regional cortical blood flow at craniotomy. Neurosurgery 2:223-229, 1978

11. Dahl A, Lindegaard KF, Russell D, et al: A comparison of transcranial Doppler and cerebral blood flow studies to assess cerebral vasoreactivity. Stroke 23:15-19, 1992

12. Devous MD Sr, Leroy RF, Homan RW: Single photon emission computed tomography in epilepsy. Semin Nucl Med 20:325-341, 1990

13. Duncan R, Bone I, Patterson J, et al: SPECT in temporal lobe epilepsy: interictal and postictal studies, in Baldy-Moulinier M (ed): Focal Epilepsy: Clinical Use of Emission Tomography. London: John Libbey, 1990, pp 79-95 
14. Duncan R, Patterson J, Roberts R, et al: Ictal/postictal SPECT in the pre-surgical localisation of complex partial seizures. J Neurol Neurosurg Psychiatry 56:141-148, 1993

15. Dymond AM, Crandall PH: Oxygen availability and blood flow in the temporal lobes during spontaneous epileptic seizures in man. Brain Res 102:191-196, 1976

16. Engel J Jr, Ojemann GA: The next step, in Engel J Jr (ed): Surgical Treatment of the Epilepsies, ed 2. New York: Raven Press, 1993, pp 319-329

17. Ewing JR, Robertson WM, Brown GG, et al: 133-Xenon inhalation: accuracy in detection of ischemic cerebral regions and angiographic lesions, in Wood JH (ed): Cerebral Blood Flow.

Physiologic and Clinical Aspects. New York: McGraw-Hill, 1987, pp 202-219

18. Franck G, Sadzot B, Salmon E, et al: Regional cerebral blood flow and metabolic rates in human focal epilepsy and status epilepticus. Adv Neurol 44:935-948, 1986

19. Gaines C, Carter LP, Crowell RM: Comparison of local cerebral blood flow determined by thermal diffusion and hydrogen clearance. Stroke 14:66-69, 1983

20. Gibbs FA, Lennox WG, Gibbs EL: Cerebral blood flow preceding and accompanying epileptic seizures in man. Arch Neurol Psychiatry 32:257-272, 1934

21. Horsley V: An address on the origin and seat of epileptic disturbance. Br Med J 1:693-696, 1892

22. Ingvar D: Regional cerebral blood flow in focal cortical epilepsy. Stroke 4:359, 1973 (Abstract)

23. LaManna MM, Sussman NM, Harner RN, et al: Initial experience with SPECT imaging of the brain using I-123 p-iodoamphetamine in focal epilepsy. Clin Nucl Med 14:428-430, 1989

24. Latchaw RE, Hu X, Ugurbil K, et al: Functional magnetic resonance imaging as a management tool for cerebral arteriovenous malformations. Neurosurgery 37:619-626, 1995

25. Lavy S, Melamed E, Portnoy Z, et al: Interictal regional cerebral blood flow in patients with partial seizures. Neurology 26:418-422, 1976

26. Lee BI, Markland ON, Wellman HN, et al: HIPDM single photon emission computed tomography brain imaging in partial onset secondarily generalized tonic-clonic seizures. Epilepsia 28:305-311, 1987

27. Lee B, Markland O, Wellman H, et al: HIPDM-SPECT in patients with medically intractable complex partial seizures. Ictal study. Arch Neurol 45:397-402, 1988

28. Leiderman D, Balish M, Bromfield E, et al: Comparison of interictal FDG and 15O-H2O PET scanning in patients with uncontrolled complex partial seizures. Neurology 39(Suppl 1):301, 1989 (Abstract)

29. Magistretti PL, Uren RF: Cerebral blood flow patterns in epilepsy, in Nisticò G, Di Perri R, Meinardi H (eds): Epilepsy: An Update on Research and Therapy. New York: Alan R Liss, 1983, pp 241-247

30. Melamed E, Lavy S, Bentin S, et al: Reduction in regional cerebral blood flow during normal aging in man. Stroke 11:31-35, 1980

31. Newton MR, Berkovic SF, Austin MC, et al: Postictal switch in blood flow distribution and temporal 
lobe seizures. J Neurol Neurosurg Psychiatry 55:891-894, 1992

32. Ochs RF, Yamamoto L, Gloor P: Correlation between the positron emission tomography measurement of glucose metabolism and oxygen utilization with focal epilepsy. Neurology 34(Suppl 1):125, 1984 (Abstract)

33. Penfield W, von Santha K, Cipriani A: Cerebral blood flow during induced epileptiform seizures in animals and man. J Neurophysiol 2:257-267, 1939

34. Penfield W: The evidence for a cerebral vascular mechanism in epilepsy. Ann Int Med 7:303-310, 1933

35. Penfield W: Remarks on incomplete hypotheses for the control of cerebral circulation. J Neurosurg 35:124-127, 1971

36. Podreka I, Suess F, Goldenberg G, et al: Initial experience with technetium-99m HM-PAO brain SPECT. J Nucl Med 28:1657-1666, 1987

37. Rowe CC, Berkovic SF, Austin MC, et al: Patterns of postictal cerebral blood flow in temporal lobe epilepsy: qualitative and quantitative analysis. Neurology 41:1096-1103, 1991

38. Rowe CC, Berkovic SF, Sia STB, et al: Localization of epileptic foci with postictal single photon emission computed tomography. Ann Neurol 26:660-668, 1989

39. Ryding E, Rosen I, Elmqvist D, et al: SPECT measurements with 99mTc-HM-PAO in focal epilepsy. J Cereb Blood Flow Metab 8 (Suppl 6):S95-S100, 1988

40. Sackellares JC, Abou-Khalil BW, Siegel GJ, et al: PET studies of interictal, ictal and postictal changes in local cerebral blood flow in temporal lobe epilepsy. Neurology 36(Suppl 1):338, 1986 (Abstract)

41. Sioutos PJ, Carter LP, Weinand ME, et al: Intraoperative measurement of peritumoral regional cortical cerebral blood flow. Oncol Reports 3:593-596, 1996

42. Sioutos PJ, Orozco JA, Carter LP, et al: Continuous regional cerebral cortical blood flow monitoring in head-injured patients. Neurosurgery 36:943-950, 1995

43. Stefan H, Bauer J, Feistel H, et al: Regional cerebral blood flow during focal seizures of temporal and frontocentral onset. Ann Neurol 27:162-166, 1990

44. Stefan H, Pawlik G, Bocher-Schwarz H, et al: Functional and morphologic abnormalities in temporal lobe epilepsy: a comparison of interictal and ictal EEG, CT, MRI, SPECT and PET. J Neurol 234:377-384, 1987

45. Weinand ME: Arteriovenous malformations and epilepsy, in Carter LP, Spetzler RF (eds): Neurovascular Surgery. New York: McGraw-Hill, 1995, pp 933-956

46. Weinand ME, Carter LP: Surface cortical cerebral blood flow monitoring and single photon emission computed tomography: Prognostic factors for selecting temporal lobectomy candidates. Seizure 3:55-59, 1994

47. Weinand ME, Carter LP, Patton DD, et al: Long-term surface cortical cerebral blood flow monitoring 
in temporal lobe epilepsy. Neurosurgery 35:657-664, 1994

48. Weinand ME, El-Saadany WF, Carter LP, et al: Temporal lobe ischemia and epileptogenicity: long-term cortical cerebral blood flow analysis of sequential seizures. Surg Forum 46:574-575, 1995

49. Weinand ME, El-Saadany WF, Labiner DM, et al: Subdural strip electrode monitoring and surgical decision making in refractory epilepsy: validity and prognostic value of noninvasive localizing data. J Epilepsy 8:131-138, 1995

50. Weinand ME, Wyler AR, Richey ET, et al: Long-term ictal monitoring with subdural strip electrodes: prognostic factors for selecting temporal lobectomy candidates. J Neurosurg 77:20-28, 1992 51. Wood JH, Carter LP: Cerebral blood flow, in Carter LP, Spetzler RF (eds): Neurovascular Surgery. New York: McGraw-Hill, 1995, pp 127-142

52. Wyler AR: The surgical treatment of epilepsy, in Seidenberg M, Hermann B (eds): Childhood Epilepsies: Neuropsychological, Psychosocial and Intervention Aspects. New York: John Wiley \& Sons, 1989, pp 173-188

53. Wyler AR, Burchiel KJ, Ward AA Jr: Chronic epileptic foci in monkeys: correlation between seizure frequency and proportion of pacemaker epileptic neurons. Epilepsia 19:475-483, 1978

54. Wyler AR, Ojemann GA, Lettich E, et al: Subdural strip electrodes for localizing epileptogenic foci. J Neurosurg 60:1195-2000, 1984

55. Yamamoto Y, Ochs R, Gloor P, et al: Patterns of rCBF and focal energy metabolic changes in relation to electroencephalographic abnormality in the interictal phase of partial epilepsy, in Baldy-Moulinier M, Ingvar D, Meldrum B (eds): Cerebral Blood Flow, Metabolism and Epilepsy. London: John Libbey, 1983, pp 51-62

Manuscript received September 13, 1996.

Accepted in final form October 17, 1996.

This paper was presented in abstract form at the annual meeting of the American Association of Neurological Surgeons, Minneapolis, Minnesota, April 27-May 2, 1996.

Address reprint requests to: Martin E. Weinand, M.D., Division of Neurosurgery, Arizona Health Sciences Center, Tucson, Arizona 85724.

\section{Click here to view Editor's Perspective.}

